\title{
Means Towards the end: Enhancing Language Skills through Collaborative assignments in Literature in English
}

\author{
Bazimaziki Gabriel $^{1 *}$, Mukadisi Florence ${ }^{2}$, Nyandwi Gilbert ${ }^{3}$, Twahirwa Jean \\ Bosco $^{4}$
}

\begin{abstract}
${ }^{1}$ University of Rwanda, College of Education, Department of Humanities and Language Education, P.O BOX 55 Rwamagana- Rwanda. ${ }^{2}$ Department of Languages and Entrepreneurship, Rwanda Polytechnic / College of Musanze, P.O.Box 226, Musanze, Rwanda ${ }^{3}$ University of Rwanda, Department of Humanities and Language Education, P.O Box 55 Rwamagana, Rwanda

* Main Author
\end{abstract}

\begin{abstract}
The aim of this paper was to throw light on group assignments in literary subjects as a means to enhance communication skills with particular interest in undergraduate one students who have learnt "Introduction to Literature in English". The study involved Cusoe Joe's Taxonomy of Specific Cooperative learning Structure which can be applied in different contexts for distinctive purposes. Four research questions guided this study such as (1) How are students interested in group assignments? (2) To what extent do group works in Literature in English engage learners (3) what are the challenges that impede effective group works and (4) how can these challenges be addressed? The researchers used both qualitative and quatitative analysis of data generated from 58 respondents selected basing on Morgan and Krejcie's sample size determination. Analysis of findings revealed that majority of students are very much interested in group assignments in Literature in English because they enhance communication skills through interaction. However, factors such as mixed combinations coupled with fear of practice and little English communication skills militate against the effective collaborative works. It was recommended that the twio parts concerned with the teaching and learning play their parts each to grapple with these challenges.
\end{abstract}

Keywords - Students' interest, Literature in English, language skills, group assignment, cooperative learning, Crusoe's Taxonomy, learner- centered.

\section{INTRODUCTION AND BACKGROUND}

The modern methodology of teaching and learning promotes the learner - centered approaches to the expense of traditional paradigm where the teacher had become the center of everything. With Competence-based curriculum implementation, literary subjects have been a good ground for learners to show what they really know so that teachers can start from where learners' ability ends by engaging them more effectively in their learning. In this perspective, teachers can choose activities that will involve learners to participate and, inherently, group tasks hold a big part for this exercise to be carried out successfully.

ISSN: $2456-7620$

https://dx.doi.org/10.22161/ijels.52.26
According to Ha Le et al.(2018), teachers use collaborative learning to develop both cognitive and collaborative skills for students, to improve their problem solving skills and helping skills, thus to promote and advance social interactions. In the same line, Mutwarasibo (2013) discussed the merits of group- based learning as one aspect of studentcentered approach and contended that this kind of method engages learners by enabling them to discuss, listen, write and reflect on content, ideas, issues and concerns, thus what he termed meaning construction. Actually, this is one of the means to improve learners' communication skills. As they discuss and interact, they will be listening to one another and decide on what to include in their answer, and write it. Inherently, when group members participate equally, 
although it is often time hard if not impossible, it will be more beneficial to them as they will be using one another's knowledge and skills rather than working individually which limits exposure to colleagues' views.

Generally, group assignments intend to help learners teach among themselves. More importantly, their learning outcomes will be largely dictated by the quality of discussion and argumentation they create themselves making it more profitable, more collective than individual. According to Scarger et al.(2016), explaining things to one another and discussing the subject matter may lead to deeper understanding, to recognition of misconceptions, and to the strengthening of connections between new information and previously learned information. The same authors come up with a point that uneven participation is one of the factors impeding the effective collaboration, either due to "power differences, not to disinterest or laziness." This implies that group management and members' ability and how they are trained to work collectively are among other factors that can affect learning through group work (Theobald et al, 2017). In the same vein, Ha le et al.(2018) identified factors such as students' lack of collaborative skills and free-riding. On the one hand, this is reflected in students' failure to accepting opposing view points, lack of skills to giving elaborate explanations on the one hand, these authors explain it that some peers contribute most, while others work less, and some do not even put in effort when completing their own tasks. Consequently, this affect negatively students' collaborative experiences.

\section{PROBLEM STATEMENT}

Group work assignments are part of formative evaluations whose main aim is assessment for learning so as to prepare well for summative assessment. In Literary subjects, continuous assessment ordinarily augurs students' improvement not only at subject content level but also enhancement of the four language skills such as listening, writing, reading and speaking. The saying that "So many heads so many mind" coheres in meaning with a similar aphorism which posits that "Union is power". In academic field, the two sayings can apply particularly when students are assigned a task in the process of teaching and learning. In literary subjects, the implementation of the Competence Based Curriculum (CBC) which involves learner's competence rather than teacher knowledge, requires more collaborative works than individual ones.
However, the researchers' experience in teaching literary subjects reveals that many students are happy when assigned a group task than individual; not because they all participate and learn from one another through interaction, but because some of the weak students don't work and leave the works for the strong who would carry the burden for the whole group. Related to this, during group works presentation before the class, some of the group members prove to have not participated as they fail to convey the content and results of what they have come up with during their research on the topic assigned. In fact, the whole task is affected by challenges as outlined in $\mathrm{Ha} \mathrm{Le}$, et al.(2018), particulary lack of collaborative skills, characterized by low attention to accepting opposing ideas, to asking for help and building trust among other things; free-riding whereby some contribute more while others work less or even engage no efforts; and competence status whereby the competent students are very influential by imposing their ideas to the rest of the group. According to the same authors, friedship feelings in the group inhibits them from working objectively. This triggered the researchers to carry out a study in hopes of finding out students' views about this kind of continuous assessment for learning.

\section{Objectives and study questions}

The aim of this study was to explore students' views about group tasks in literary subjects with particular emphasis on Introduction to Literature in English, a course taught year one students in University of Rwanda, College of Education. Further, the researchers wanted to demonstrate that group work activities engage learners by promoting interaction among learners. Finally, they wanted to identify challenges impeding the effective collaborative assessment among learners and suggest possible remedies. In line with these objectives, the study sought to answer the following questions: (1) How are students interested in group assignments? (2) To what extent do group works in Literature in English engage learners (3) what are the challenges that impede effective group works and (4) how can these challenges be addressed? Based on these research questions, the researchers hinged on the theories and methodology discussed in the following section..

\section{THEORIES AND METHOD}

This study hinges on Cusoe Joe's Taxonomy of Specific Cooperative - learning Structures Strategies which, according to the same author, may be applied in different 
contexts for distinctive purposes. Among other things, the taxonomy holds that (1) Cooperative-learning structures actively involves students in their learning process; (2) capitalizes on the power of the peer group to promote students'learning and academic achievement, thus promoting peer interdependence, teamwork and mutual supports; and (3) infuses the learning process with procedural variety that serves to increase student attention, interest, and motivation. Particularly, the study is geared by Havru's "Companionship" Method as well described in Cusoe(2002) below:

“ ...students are pre-tested for performance in a specific skill or content area and the instructor forms dyads comprised of students who differ in their level of achievement or performance on the pre-test. Students are then presented with a learning task (or a series of learning tasks) relating to the content or skill being taught, and they work together on the learning task until each one of them understands and masters it. Each partner is then tested individually on a post-test." $(p .10)$

Elsewhere, this study uses a mixed- method approach which integrates quantitative and qualitative data within a single study(Wisdom and Creswell, 2013). The study involved year one students who studied Literature in English. Basing on Morgan and Krejcie(1970), a sample of 58 was selected from 65 population in the combinations of Literature. Questionnaire was distributed to them as a means to collect data. Both closed and open questions were used in this questionnaire covering the themes related to students' views about group work assignments, challenges affecting group work exercises and how to address them. For closed questions, the researchers deemed relevant to use A fourpoint Likert scale ranging from 1 to 4 , that is 1 . Strongly agree; 2. Agree; 3. Disagree; and 4. Strongly Disagree. Further, two open questions were used in a bid to help respondents suggest what should be done by learners and lecturers to mitigate the challenges affecting effective group works.

\section{PRESENTATION OF RESULTS}

\section{Demographic situation of respondents}

\begin{tabular}{|c|c|c|c|}
\hline \multirow{2}{*}{\multicolumn{2}{|c|}{ Categories }} & \multicolumn{2}{|c|}{ Frequency and percentages } \\
\hline & & \multirow{2}{*}{$\begin{array}{l}\text { Frequency } \\
36\end{array}$} & \multirow{2}{*}{$\begin{array}{l}\% \\
62.1\end{array}$} \\
\hline \multirow{2}{*}{ Gender of respondents } & Male & & \\
\hline & Female & 22 & 37.9 \\
\hline Total & 2 & 58 & 100 \\
\hline \multirow{5}{*}{ Age of respondents } & $18-19$ & 10 & 17.2 \\
\hline & $20-21$ & 22 & 37.9 \\
\hline & $22-23$ & 14 & 24.1 \\
\hline & $24-25$ & 10 & 17.2 \\
\hline & $26-27$ & 2 & 3.4 \\
\hline Total & 5 & 58 & 100 \\
\hline \multirow{3}{*}{ Combinations of respondents } & ELE & 50 & 86.2 \\
\hline & LEE & 4 & 6.9 \\
\hline & LHE & 4 & 6.9 \\
\hline Total & 3 & 48 & 100 \\
\hline
\end{tabular}

The above table is concerned with respondents' demographic presentation. The table reveals two categories of respondents' gender such a female and male whereby on a total of 58 respondents, $36(62.1 \%)$ are male while
$22(37.9 \%)$ are female; five respondents's age categories such as 10 respondents $(17.2 \%)$ with age 18-19; 22 respondents $(37.9 \%)$ under the category of $20-21 ; 14$ respondents $(24.1 \%)$ in the category of $22-23) ; 10$ 
respondents (17.2\%) with age between 24-25; and 2 (3.4\%) in the category of 26-27. Following closely, the table reveals that respondents come from three combinations in which Literature in English is a common subject. These are English- Literature with Education (ELE) having majority of respondents as they are 50(86.2\%), then LiteratureEconomics with Education(LEE) and Literature - Hitory with Education( LHE) both combinations having 4 respondents $(6.9 \%)$ for each.

Table presenting students' views about group work assignments in Literature in English

\section{Item 1: Students interests in doing group work assignments}

In the table below, students reveal how their interest in doing literature group assignments stands. A total of ten closed interrelated questions were formulated basing on students'interest and why. Information was generated using a four-point Likert Scale such as Strongly Agree (SA), Agree (A), Disagree (D) and Stongly Disagree (SD) whereby respondents selected their choices accordingly. Thus, their views are presented as follow:

\begin{tabular}{|c|c|c|c|c|c|c|c|c|c|c|}
\hline \multirow[t]{3}{*}{ STATEMENTS } & \multicolumn{8}{|c|}{ STUDENTS' VIEWS } & \multirow{2}{*}{\multicolumn{2}{|c|}{$\begin{array}{l}\text { Cumulative } \\
\text { frequency }\end{array}$}} \\
\hline & \multicolumn{2}{|c|}{$\begin{array}{l}\text { Strongly } \\
\text { agree }\end{array}$} & \multicolumn{2}{|c|}{ agree } & \multicolumn{2}{|c|}{ Disagree } & \multicolumn{2}{|c|}{$\begin{array}{l}\text { Strongly } \\
\text { disagree }\end{array}$} & & \\
\hline & $\mathbf{F}$ & $(\%)$ & $\mathbf{F}$ & $(\%)$ & $\mathbf{F}$ & $(\%)$ & $\mathbf{F}$ & $(\%)$ & $\mathbf{F}$ & $\%$ \\
\hline $\begin{array}{l}\text { I like group assignments because they promote interaction } \\
\text { among us }\end{array}$ & 41 & 70.7 & 16 & 27.6 & 1 & 1.7 & 0 & 0.0 & 58 & 100 \\
\hline $\begin{array}{l}\text { I am very much interested in group works because they save } \\
\text { time }\end{array}$ & 15 & 25.9 & 33 & 56.0 & 10 & 17.2 & 0 & 0.0 & 58 & 100 \\
\hline $\begin{array}{l}\text { I am interested in group assignments in Literaturein English } \\
\text { because they help me know about what others have read }\end{array}$ & 41 & 70.7 & 17 & 29.3 & 0 & 0.0 & 0 & 0.0 & 58 & 100 \\
\hline $\begin{array}{l}\text { I am interested in group assignments in Literature in English } \\
\text { for they help me to use language for various purposes }\end{array}$ & 36 & 62.1 & 21 & 36.2 & 1 & 1.7 & 0.0 & 0.0 & 58 & 100 \\
\hline $\begin{array}{l}\text { I am interested in group works in Literature in English } \\
\text { because they help me improve my language skills }\end{array}$ & 50 & 86.8 & 8 & 13.2 & 0 & 0.0 & 0 & 0.0 & 58 & 100 \\
\hline $\begin{array}{l}\text { I am not interested in group works in Literature in English } \\
\text { because they don't help me think deeply }\end{array}$ & 2 & 3.4 & 23 & 39.7 & 33 & 56.9 & 0 & 0.0 & 58 & 100 \\
\hline $\begin{array}{l}\text { I do not like group assignments in Literature in English } \\
\text { because I am unable to comply with colleagues' plans }\end{array}$ & 0 & 0.0 & 1 & 1.7 & 23 & 39.7 & 34 & 58.6 & 58 & 100 \\
\hline $\begin{array}{l}\text { Group works in Literature in English bore me because it is } \\
\text { hard to me to discuss with others in English }\end{array}$ & 0 & 0.0 & 2 & 3.4 & 16 & 27.6 & 40 & 69.0 & 58 & 100 \\
\hline $\begin{array}{l}\text { I am not interested in group works in Literature in English } \\
\text { because I feel comfortble when I work alone }\end{array}$ & 1 & 1.7 & 1 & 1.7 & 18 & 31.0 & 38 & 65.5 & 58 & 100 \\
\hline $\begin{array}{l}\text { I am not interested in group works in Literature in English } \\
\text { because many students do not bring their contributions }\end{array}$ & 0 & 0.0 & 2 & 3.4 & 26 & 44.8 & 30 & 51.7 & 58 & 100 \\
\hline
\end{tabular}


Item 3: Table showing respondents' views about challenges affecting group work exercises in Literature in English

\begin{tabular}{|c|c|c|c|c|c|c|}
\hline \multirow[t]{3}{*}{ STATEMENTS } & \multicolumn{4}{|c|}{ Students' views } & \multirow{2}{*}{\multicolumn{2}{|c|}{$\begin{array}{l}\text { Cumulative } \\
\text { Frequency }\end{array}$}} \\
\hline & \multicolumn{2}{|c|}{ Yes } & \multicolumn{2}{|c|}{ No } & & \\
\hline & $\mathrm{F}$ & $(\%)$ & $\mathrm{F}$ & $(\%)$ & $\mathrm{F}$ & $\%$ \\
\hline Fear of practice is a big challenge for me in learning Literature in English & 43 & 74.1 & 15 & 25.9 & 58 & 100 \\
\hline Group works in Literature in English do not enrich my personal research & 6 & 10.3 & 52 & 89.7 & 58 & 100 \\
\hline $\begin{array}{l}\text { Mixed classes from different combinations is a barrier to effectively work in } \\
\text { groups }\end{array}$ & 31 & 53.4 & 27 & 46.6 & 58 & 100 \\
\hline $\begin{array}{l}\text { Lack of enough room for participation in group works impedes my language skills } \\
\text { improvement }\end{array}$ & 29 & 50.0 & 29 & 50.0 & 58 & 100 \\
\hline My low level of English is a big challenge to work with others in group assignments & 26 & 44.8 & 32 & 55.2 & 58 & 100 \\
\hline My little interest in literary subjects affects my participation in group assignments & 15 & 25.9 & 43 & 74.1 & 58 & 100 \\
\hline The types of questions is a big challenge to me in group assignments & 6 & 10.3 & 52 & 89.7 & 58 & 100 \\
\hline $\begin{array}{l}\text { Little time allocated for group assignments in Literature in English impedes } \\
\text { students to work effectively }\end{array}$ & 26 & 44.8 & 32 & 55.2 & 58 & 100 \\
\hline
\end{tabular}

In the above table, respondents were asked eight closed questions regarding challenges impeding effective group works in Literature in English subject. Particular interest was directed to issues such as mixed classes, students' fear of practice, their interest in collaborative and personal learning, time allocated, and types of questions given as group works.
Item 3: Way forward: Mitigating challenges impeding effective group works in literature

This section is concerned with way forward. The researchers present respondents' views of how challenges that impede effective group works can be well mitigated. The researchers posed the questions involving the role of both learners, teacher and the institution as presented in the table below:

\begin{tabular}{|l|l|}
\hline What students should do & Teachers' role \\
\hline Do more research to find more ideas & Make a follow up and supervise the work \\
Feel free and participate actively & Indicate the resources to students and guide them \\
$\begin{array}{l}\text { Be confident and not feel complexed among group } \\
\text { members }\end{array}$ & Correct students' language errors \\
Avoid letting one individual ideas influence the group & Play a part in the group formation \\
members & Encourage students and give them enough time \\
Respect and help one another & Give feedback after group works are presented \\
Stick to English during the work as it is a medium of & Be in touch with students so as to assist them when in \\
instruction & need \\
Cooperate and collaborate in a brotherly climate & Consider that students are from different backgrounds \\
Avoid dodging class and group tasks as well & Assign questions that will help students to discuss and \\
Feel responsible and manage their time effectively & enhance communication and interaction \\
\hline
\end{tabular}




\section{DISCUSSION OF FINDINGS}

Discussion in this study takes much account into Cusoe (2002) who believes that Cooperative-learning structures actively involves students in their learning process. Actually, when learners are interested in working collaboratively, the idea is that they can achieve more as they are putting efforts together. In this study, the interest of learners in group assignment because it promotes interaction among them is highly confirmed as $41(70.7 \%)$ strongly agree while $16(27.6 \%)$ agree with the statement. This leads to the conclusion that the role of group assignment especially in literature in English promotes interaction, thus enhancing the communication skills of learners. From this situation, group assignments actively engage learners and are therefore a means to improving communication skills. Looking back into the table, one will find that majority of respondents, that is $41(70.7 \%)$, strongly agree, while $17(29.3)$ agree, that literature assignments done in groups are a means through which learners know about what others have read. The fact that they learn from one another is an important end which positively coheres with the view of Bazimaziki (2019) who asserts that literary subjects engage learners and enables them to interact, think critically and develop various language skills. Still in the same line of students' interest in group assignments, majority of respondents, that is 50 (86.8\%) who strongly agree, and $8(13.2 \%)$ who agree, comfirm that they are interested in group works in Literature in English because through it they improve their communication skills. This is another important means to an end. More importantly, none of the respondents strongly agree that they do not like group works in Literature in English, nor do they agree that these works done in groups bore them. Rather, majority, that is 40 ( 69\%) strongly disagree with their statement that group works in Literature in English bore them because it is hard to them to discuss with others in English. Following the views of many respondents (32 which makes 55.2\%), it is confirmed that their little English is not a challenge impeding them to interact with others, and it is clear that they are not bored when working with others. If they are interested, it is a way to improving by learning from each other.

Looking back to the challenges impeding learners to do group works effectively, majority, that is $43(74.1 \%)$ confirmed that fear of practice is a big challenge in learning Literature in English.Thus, this is a barrier to effectively participate in the discussion with others during their works. This is connected with their stand that mixed classes from different combinations is a barrier to effectively work in groups as revealed by 31 respondents $(53.4 \%)$. The idea is that when combinations are mixed while they do not have the same literary background, it can affect their discussions because the less competent will not participate adequately as the stronger will hold a big room. This is justified by another respondents' stand on the statement that lack of enough room for participation in group works impedes their language skills improvement. As the table reveals, 29(50\%) respondents are for this statement while others 29(50\%) are against. This implies that half of respondents participate conveniently while another half do not; which means participation is impeded for some to some extent. This is linked with students's level and motivation to learning where the more able impose their points to be included into the answers. However, it is another means for the weaker to reach their end as they can be benefitting from their more knowledgeable mates.

When one looks at the information presented in the table concerning item three about the mitigation of challenges, it is important to mention that these are qualitative data collected using two open questions about (1) what students should do for their group works to be effective and (2) the role of the teachers for students to carry out effective group works successfully. In learning process, both students and teachers should play their part each one so that the exercise can be successful. This is the reason why the researchers wanted to know about students' views as regard their part and their teachers' role for group works in Literature in English to be effective. Lenard and Lenard (2018) suggested that in order to overcome challenges impeding effective teaching and learning, students should be put into smaller groups, and that more academic skill-based classes be practised while availing better course books; and finally promote a closer cooperation with subject specialists. Literature in English is concerned with the two authors' view. On the first question concerning the role of the learners, respondents suggested that students should be engaged in doing more research. The more they research, the more they find out more complementary and congruous ideas. If this is done, it will be an important means towards feeling more confident and participating actively among the groupmates without feeling complexed as they will be using information from reliable sources. This reduces the culture of passiveness among groupmates whereby the ideas of the stronger students influence the weaker. Added to this, respondents suggested mutual respect and help among the group members. This 
enhances cooperation and collaboration as some of respondents put it. It is another way to reach a positive end as they will be pulling together towards a successful work done by many hands. Moreso, respondents suggested to stick to English during the work. Of course, English is a medium of instruction in Rwandan education system but a second language to Rwandese. Sticking to it while doing a literary group work is one means to know it. Another suggested point is that they should avoid dodging class and group tasks as well. Dodging class is not a means to a successful learning. Rather, it is a barrier to intended learning outcomes.This is the reason why students must feel responsible for their learning.

The second question targeted the teacher's role. The researchers wished to know about respondents' stand on the role that should be played by the teacher for group works to be carried out successfully. In fact, a group activity entails collaboration and asks different people in need. It is a guided activity whereby a teacher should get engaged for a positive end in connection with Lenard and Lenard (2018) who put it that the teacher can help learners in tandem with ability, know their problems and solve them accordingly. In that connection, students suggested that teachers should indicate the needed and relevant resources to be consulted. This is a needed support for learners to be more motivated at work. Teachers should also play a part in the group formation; make a follow up and supervise the work where possible. When students make groups themselves, one can find the stronger in one group and the weaker in another, a situation which can impede the teacher's goal of helping learners to teach among themselves as they have different background and competences. Respondents suggested that lecturers should assign questions that help students to discuss openly, thus a means to enhance communication and interaction among them.

\section{CONCLUSION AND RECOMMENDATION}

Literary subjects are taught not only to know about great writers from different cultures and civilization, but also as a means to enhance language skills. In Rwandan context in particular, Literature in English is a tool to learning English, a second language used in various domains in that country. As group work entails assessment for learning, Literature in English cannot be exception. Thus, the aim of this study was to demonstrate how through group works in Literature in English, when learners are interested and guided effectively, they can improve their language skills, learn from one another and achieve more by doing personal research related to their course. Active participation is thus recommended to avoid passiveness which prevents learning through group interactions, thus a means to "rekindle even the passive learners to get involved in a fun way to learn and practice language skills". Notwithstanding the findings in this single study, a follow up should investigate the demerits of group assignments in Literature in English course so as to bridge some gaps.

\section{REFERENCES}

[1] Bazimaziki, G. (2019) Students' Perceptions of Using Literary Genres to enhance English Language Proficiency. International Journal of English Literature and Social Sciences (IJELS), 4(2), 221-227.

[2] Cuseo, J. B. (2002). Igniting student involvement, peer interaction, and teamwork: A taxonomy of specific cooperative learning structures and collaborative learning strategies. Stillwater, OK: New Forums Press.

[3] Ha Le, Jeroen Janssen \& Wubbels Theo(2018)Collaborative Learning Practices: Teacher and student perceived as obstacles to effective student collaboration. Cambridge Journal of Education. 48(1), 103-122.

[4] Lenard, D. Božić \& Lenard, I. (2018) Examining Pedagogical content knowledge of ESP teachers. The Journal of Teaching English for Specific and Academic Purpose. 6(3), 353-364.

[5] Morgan Daryle W. \& Krejcie Robert V. (1970) Determining sample size for Research Activities. Education and Psychological Measurement. 30(1970) 607-610.

[6] Mutwarasibo, F. (2013) Understanding Group-based Learning in Academic Context. Rwandan Students' Reflexions on Collaborative Writing and Peer Assessmnts. Linkoping: LiU ( PhD Thesis).

[7] Scarger K., Boonstra J., Petters T., Vulperhorst J., Weigant F. (2016) Collaborative Learning in Higher Education: Evoking Positive Interdependance. CBE—Life Sciences Education. 15:ar69, 1-9.

[8] Theobald EJ, Eddy SL, Grunspan DZ, Wiggins, BL, Crowe, AJ (2017) Students perception of group dynamics predicts individual performance: Commfort and equuitty matter: PLos One 12(7), 1-16, e0181336. https://doi.org/10.1371/journal.pone.0181336

[9] Wisdom, J. \&Creswell, J.W. (2013), Mixed Methods: Integrating Quantitative and Qualitative Data Collection and Analysis While Studying Patient-Centered Medical Home Models. In Agency for Healthcare Research and Quality No. 13-0028-EF. AHRQ Publication. Rockville. 